\title{
KESENJANGAN PENGHASILAN MENURUT GENDER DI INDONESIA
}

\begin{tabular}{|c|}
\hline Lusiyanti \\
Universitas Indonesia \\
aa2005ad@gmail.com
\end{tabular}

Diterima: September 2019; Disetujui: Oktober 2020

\begin{abstract}
Gender gaps occur in various countries in the world as described by the World Economic Forum through the Global Gap Gender Index (GGGI). One of the aspects of GGGI is from an economic perspective, namely participation and opportunity. This study aims to measure how big the income gap that occurs by gender in Indonesia. Using the 2019 Sakernas data and the Blinder-Oaxaca decomposition method, the results show that the income gap between men and women in Indonesia is 0.4282 percentage points, which means that on average men's income is 42.82 percent higher than that of women. The contribution of the discrimination factors is more dominant than the endowment factors to the total gap that occurs. Endowment factors such as age, working hours, education, type, and employment only contributed 3.55 percent of the total gap, while the contribution of the discrimination factor was 96.45 percent.
\end{abstract}

Keyword: blinder-oaxaca, gender income gap, sakernas

Abstraksi. Kesenjangan gender terjadi di berbagai negara di dunia seperti yang dijelaskan oleh World Economic Forum melalui Global Gap Gender Index (GGGI). Salah satu aspek GGGI adalah dari segi ekonomi yaitu participation and opportunity. Penelitian ini bertujuan untuk mengukur seberapa besar kesenjangan penghasilan yang terjadi menurut gender di Indonesia. Dengan menggunakan data Sakernas 2019 dan metode dekomposisi Blinder-Oaxaca diperoleh hasil bahwa kesenjangan penghasilan antara laki-laki dan perempuan di Indonesia sebesar 0,4282 poin persentase, yang artinya secara rata-rata penghasilan laki-laki lebih tinggi 42,82 persen dibandingkan dengan perempuan. Kontribusi faktor diskriminasi lebih dominan dibandingkan faktor endowment terhadap total kesenjangan yang terjadi. Faktor endowment seperti umur, jam kerja, pendidikan, jenis dan lapangan pekerjaan hanya berkontribusi sebesar 3,55 persen dari total kesenjangan yang terjadi, sementara kontribusi faktor diskriminasi sebesar 96,45 persen.

Kata kunci: blinder-oaxaca, kesenjangan penghasilan, sakernas

\section{PENDAHULUAN}

Kesenjangan gender terjadi di hampir setiap negara di dunia. Bahkan sejak tahun 2006 World Economic Forum mulai memperkenalkan yang namanya Global Gap Gender Index (GGGI) untuk menangkap besarnya kesenjangan berbasis gender dengan berfokus pada kesenjangan secara nasional dari segi ekonomi, pendidikan, kesehatan dan politik. Indonesia sendiri berdasarkan ranking GGGI tahun 2020 berada pada urutan ke 85 dari 153 negara di dunia. Capaian yang masih cukup rendah dari komposisi penyususun indeks tersebut salah satunya adalah dari segi ekonomi yaitu dalam hal participation and opportunity. Sejak dua dekade lebih tingkat partisipasi angkatan kerja perempuan Indonesia cenderung stagnan di kisaran 50 persen, sementara laki-laki sudah mencapai lebih dari 80 persen. Rendahnya tingkat partisipasi perempuan selain akibat budaya patriartki juga dapat disebabkan oleh diskriminasi setelah mereka masuk ke pasar kerja. Diskriminasi dalam hal ini terkait dengan 
penghasilan yang diperoleh. Perbedaan penghasilan atau akses ke pekerjaan tertentu pada dua orang dengan produktifitas yang sama tetapi diperlakukan berbeda merupakan diskriminasi (Jacobson, 1994).

Pada Agustus 2019 rata-rata upah buruh/karyawan/pegawai sebesar 2,91 juta rupiah per bulan. Laki-laki memperoleh upah rata-rata yang lebih tinggi dibandingkan dengan perempuan dan upah perempuan lebih rendah dari upah rata-rata secara nasional. Jika rata-rata upah laki-laki 3,17 juta rupiah per bulan, maka rata-rata upah perempuan hanya 2,45 juta rupiah per bulan (BPS, 2019). Penghasilan yang lebih rendah juga terjadi pada perempuan yang bekerja sebagai pekerja bebas dan wirausaha. Perempuan mendapat sekitar 30 persen lebih rendah dari laki-laki, baik dalam pekerjaan berbayar maupun wirausaha. Kesenjangan yang dijelaskan hanya sekitar seperempat dari kesenjangan dalam pekerjaan berbayar tetapi sekitar setengah dari kesenjangan dalam wirausaha (Kitae, 2015).

Untuk mengukur besarnya diskriminasi pada penghasilan antara laki-laki dan perempuan, Oaxaca dan Blinder (1973) membuat dekomposisi dari kesenjangan tersebut menjadi faktor yang dapat dijelaskan (explained/faktor endowment) dan faktor yang tidak dapat dijelaskan (unexplained/diskriminasi). Faktor endowment merupakan karakteristik yang sekiranya dapat menjelaskan adanya perbedaan penghasilan antara laki-laki dan perempuan, seperti tingkat pendidikan, umur, jenis pekerjaan dan lain sebagainya. Sedangkan faktor diskriminasi adalah perlakuan yang berbeda di pasar kerja yang tidak dapat dijelaskan melalui perbedaan karakteristik/terdapat karakteristik yang tidak diobservasi. Secara global penghasilan rata-rata perempuan lebih rendah dibandingkan dengan laki-laki. Beberapa sebab diantaranya karena faktor human capital (akses ke pendidikan yang berbeda), adanya diskriminasi dalam pekerjaan, perempuan lebih banyak bekerja pada bidang yang low skill sehingga upah juga lebih rendah dan lain sebagainya. Hasil temuan mengenai gender pay gap di Indonesia menunjukkan bahwa untuk mengurangi kesenjangan penghasilan yang terjadi yaitu dengan menetapkan kebijakan yang lebih berfokus pada perawatan anak dan juga akses pada pekerjaan paruh waktu yang lebih berkualitas (Caroline Rubin, 2020). Penelitian dengan data Sakernas 2016 juga menemukan bahwa kesenjangan upah dapat dikurangi dengan meningkatkan jam kerja, pengalaman, pendidikan dan keterampilan pekerja perempuan (Lidya \& Kadir, 2019). Di Bangladesh dekomposisi upah rata-rata perempuan 12,2 persen lebih rendah dibandingkan dengan upah rata-rata laki-laki dimana lebih dari 50 persen kesenjangan upah tersebut disebabkan oleh diskriminasi pasar kerja terhadap kaum perempuan (Rahman \& Al-Hasan, 2019).

Penelitian-penelitian sebelumnya menunjukkan adanya diskriminasi di pasar kerja yang cukup besar, berakibat pada kesenjangan upah antara laki-laki dan perempuan. Dengan menggunakan data terkini yaitu Sakernas 2019, penelitian ini bertujuan untuk mengukur seberapa besar kesenjangan penghasilan antar gender di Indonesia, apakah faktor diskriminasi masih menjadi penentu yang cukup besar pada kesenjangan penghasilan yang diperoleh perempuan dan laki-laki. Seperti yang diketahui bahwa di Indonesia sendiri memiliki sebuah Undang-Undang Ketenagakerjaan no 13 Tahun 2003 yang salah satu intinya bahwa seharusnya tidak terjadi diskriminasi gender di lingkungan 
pasar kerja. Dengan penelitian ini yang dilakukan dengan data terbaru diharapkan dapat memberikan penjelasan yang lebih terkini tentang penyebab dari kesenjangan penghasilan yang diterima antara laki-laki dan perempuan.

Pengolahan data menggunakan analisis dekomposisi Blinder-Oaxaca, dimana sebelumnya juga akan dilihat bagaimana tingkat partisipasi angkatan kerja perempuan di Indonesia agar tidak menimbulkan bias sampel pada data yang akan digunakan (Heckman, 1979).

Hipotesis dalam penelitian ini yaitu tingkat partisipasi bekerja antara laki-laki dan perempuan berbeda dimana perempuan memiliki probabilitas yang lebih kecil untuk bekerja jika sudah menikah atau memiliki anak di bawah usia 5 tahun. Perempuan memiliki penghasilan yang lebih rendah dibandingkan laki-laki dimana kontribusi dari faktor endowment tidak lebih besar dari faktor diskriminasi.

Secara ekonomi, seseorang akan memilih untuk bekerja jika upah yang tawarkan melebihi reservation wage yang dia harapkan. Jika upah yang ditawarkan masih di bawah dari reseravtion wage maka biasanya orang akan cenderung untuk memilih tidak bekerja. Keputusan untuk bekerja atau tidak juga dikaitkan dengan besarnya non-labor income yang dimiliki seseorang. Semakin besar non-labor income kecenderungan untuk tidak bekerja lebih besar/kemampuan untuk menganggur lebih besar (Borjas, 2016).

Selanjutnya ketika seseorang memutuskan untuk bekerja, dari segi pekerjaan juga terdapat pembeda yang mengakibatkan upah/penghasilan yang diterima seseorang berbeda dari yang lain. Perbedaan ini terjadi pada jenis pekerjaan yang berisiko (risky job) dan pekerjaan yang aman/tidak berisiko (safety job).
Secara teori orang-orang yang bekerja pada pekerjaan berisiko tinggi (risky job) cenderung memperoleh upah/penghasilan yang lebih besar. Besarnya upah/penghasilan ini sejalan dengan risiko yang akan diterima seseorang jika memilih jenis pekerjaan ini (Borjas, 2016).

Dalam pasar kerja perbedaan penghasilan juga terjadi menurut jenis kelamin berdasarkan teori segregasi pekerjaan, yaitu neoclasical human capital, institusional dan segmentasi pasar kerja, serts feminist (Anker, 1998). Teori neoclasical human capital mengatakan bahwa perempuan memperoleh pendapatan yang lebih rendah dibandingkan dengan laki-laki karena terkait dengan human capital perempuan yang lebih rendah. Teori sheepskin effect menunjukkan bahwa penghasilan mereka yang semakin berpendidikan lebih besar tinggi dibandingkan dengan yang tidak/kurang berpendidikan. Pendidikan dikaitkan dengan proxy untuk menilai produktifitas seseorang. Karena mayoritas perempuan berpendidikan tidak lebih tinggi dari lakilaki maka ketika masuk ke pasar kerja mereka dianggap memiliki produktifitas yang rendah (Anker, 1998).

Teori institusional dan segmentasi pasar kerja menyebutkan bahwa institusi/perusahaan mendapatkan peran yang penting dalam hal menentukan siapa saja pekerja yang akan dipekerjakan, diberhentikan, dipromosikan, dan berapa besar mereka akan dibayar. Segmentasi pasar kerja sendiri terdiri dari sektor primer dan sektor sekunder (Doeringer dan Piore, 1971). Sektor primer digambarkan dengan jenis pekerjaan yang relatif lebih baik dari segi upah, keamanan, dan kesempatan karir. Sementara sektor sekunder adalah kondisi yang sebaliknya. Oleh karena itu biasanya sektor primer diisi oleh sebagian besar 
pekerja laki-laki karena perusahaan berani mempekerjakan dan membayar mereka yang lebih berpendidikan serta lebih berpengalaman dibandingkan dengan perempuan (Anker, 1998).

Teori feminist menempatkan bahwa perempuan ada pada posisi yang lebih rendah dalam masyarakat dan keluarga. Di masyarakat, pekerjaan rumah dan mengurus anak dilihat sebagai tanggungjawab seorang perempuan, sementara laki-laki sebagai pencari nafkah. Oleh karena itu, ketika perempuan turut berpartisipasi dalam pasar kerja pada akhirnya mendorong diskriminasi pada perempuan khususnya dalam hal upah/penghasilan yang dterima (Anker, 1998).

\section{Studi Empiris Terdahulu}

Penelitian tentang partisipasi perempuan dalam angkatan kerja yang dilihat dari status bekerja serta jumlah jam kerja menunjukkan hasil bahwa status perkawinan, pendidikan primer, pendidian tinggi, usia dan pengalaman kerja berpengaruh secara signifikan terhadap status bekerja perempuan (Agustini, 2016). Selain itu, Pratomo (2017) dengan penelitiannya menggunakan data Sakernas 2015, setelah dikontrol dengan variabel lain, partisipasi kerja perempuan dan tingkat pendidikan adalah berbentuk kurva U. Tingkat partisipasi kerja perempuan tinggi pada tingkat pendidikan yang rendah kemudian menurun pada tingkat pendidikan menengah dan meningkat lagi pada tingkat pendidikan yang tinggi.

Dalam hal kesenjangan penghasilan, perempuan mendapat sekitar 30 persen lebih rendah dari laki-laki, baik dalam pekerjaan berbayar maupun wirausaha. Kesenjangan yang dijelaskan hanya sekitar seperempat dari kesenjangan dalam pekerjaan berbayar tetapi sekitar setengah dari kesenjangan dalam wirausaha (Kitae, 2015). Penelitian yang dilakukan Mardiana (2015) mendapati hasil bahwasanya di Indonesia masih terdapat kesenjangan penghasilan menurut gender sebesar 47,29 poin persentase. Kontribusi dari faktor diskriminasi lebih besar dibandingkan dengan faktor endowment seperti usia, pendidikan, tempat tinggal, jam kerja, status kegiatan, pekerjaan. Jika faktor endowment berkontribusi 12,47 persen, maka faktor diskriminasi berkontribusi 87,53 persen terhadap total kesenjangan yang terjadi. Dilihat secara lebih detail menurut status pekerjaan antara pekerja (buruh/karyawan/pegawai) dengan wirausaha di Indonesia, diskriminasi juga masih terjadi. Kesenjangan upah pada status pekerja lebih tinggi dibandingkan kesenjangan penghasilan pada status wirausaha. Jika kesenjangan upah pada pekerja sebesar 0,547 poin persentase, pada status wirausaha kesejangannya 0,424 poin persentase. Faktor diskriminasi pada pekerja 38,38 persen dan pada status wirausaha 98,25 persen (Mardiana, 2014).

\section{METODE PENELITIAN}

Data yang digunakan dalam penelitian ini adalah data Survei Angkatan Kerja Nasional (Sakernas) Agustus 2019 dari Badan Pusat Statistik (BPS). Konsep ketenagakerjaan yang digunakan BPS mengacu pada the labor force concept yang disarankan oleh International Labor Organization (ILO). Penduduk usia kerja (15 tahun ke atas) dibedakan menjadi 2 yaitu angkatan kerja dan bukan angkatan kerja. Angkatan kerja adalah penduduk usia kerja yang memiliki pekerjaan tetapi sementara tidak bekerja dan pengangguran. Sedangkan yang termasuk bukan angkatan kerja adalah mereka yang termasuk dalam usia kerja yang sedang sekolah, mengurus 
rumah tangga atau melaksankaan kegiatan lainnya selain kegiatan pribadi (BPS, 2019).

Dari sampel data Sakernas tersebut terdapat sebanyak 782.789 penduduk berusia 15 tahun ke atas dengan 532.213 orang merupakan angkatan kerja dan 250.576 lainnya termasuk bukan angkatan kerja. Unit analisis dalam penelitian ini adalah mereka yang termasuk angkatan kerja, baik laki-laki maupun perempuan. Dari angkatan kerja hasil Sakernas Agustus 2019 tersebut diperoleh jumlah individu yang bekerja sebanyak 510.161 orang yang terdiri dari laki-laki sebanyak 306.335 orang dan perempuan sebanyak 203.826 orang. Dari berbagai literatur penelitian sebelumnya maka variabel-variabel yang akan digunakan dalam penelitian ini terdiri dari variabel kontinu dan juga variabel dummy yang dibentuk sedemikian rupa sehingga diharapkan akan dapat lebih menjelaskan variabel terikat yang digunakan (Tabel 1).

Penelitian ini menggunakan metode analisis deskriptif dan inferensia. Analisis deskriptif digunakan untuk memberikan penjelasan mengenai variabel-variabel yang digunakan dalam penelitian. Sementara untuk analisis inferensia akan melihat perbedaan penghasilan antara laki-laki dan perempuan serta seberapa besar kesenjangannya dengan menggunakan metode dekomposisi Blinder-Oaxaca. Namun, sebelum dilakukan dekomposisi tersebut akan dibentuk model partisipasi kerja menggunakan model probit (probability unit).

Model probit dalam hal ini digunakan untuk melihat partisipasi kerja dari angkatan kerja di Indonesia, dimana variabel yang akan diteliti adalah apakah memilih bekerja atau tidak dengan mempertimbangkan variabel bebas yang dimasukan ke dalam model.

$$
\mathrm{P} *_{\mathrm{i}}=\beta_{\mathrm{p}} \mathrm{X}_{\mathrm{p}}+\varepsilon_{\mathrm{pi}}
$$

Dimana:

$\mathrm{P}^{*}$ : variabel laten yang menjelaskan keputusan partisipasi kerja

$\beta_{\mathrm{p}}$ : koefisien determinan partisipasi kerja $X_{p}$ : varabel bebas yang mempengaruhi partisipasi kerja (umur, umur ${ }^{2}$, jenis kelamin, status kawin, tingkat pendidikan, adanya balita dalam rumah tangga, status dalam rumah tangga dan inetraksi antara jenis kelamin dengan kepemilikan balita serta status perkawinan)

$\varepsilon_{\mathrm{pi}}$ : error term

Dengan memasukan variabel bebas, persamaan (1) menjadi :

$\mathrm{P} *_{\mathrm{i}}=\beta_{0}+\beta_{1}$ umur $+\beta_{2}$ umur $^{2}+\beta_{3}$ perempuan $+\beta_{4}$ kawin $+\beta_{5}$ kota $+\beta_{6} \mathrm{smp}+$ $\beta_{7} \mathrm{sma}+\beta_{8} \mathrm{smk}+\beta_{9}$ diploma $+\beta_{10}$ univ + $\beta_{11} \mathrm{krt}+\beta_{12}$ balita $+\beta_{13} \mathrm{jkbal}+\beta_{14} \mathrm{jkkwn}+$ $\varepsilon_{\mathrm{pi}}$

Variabel $\mathrm{P}{ }_{\mathrm{i}}$ adalah variabel laten yang tidak teramati karena data yang tersedia adalah bersifat kategorik. Oleh karena variabel yang teramati adalah $\mathrm{P}_{\mathrm{i}}$, maka $\mathrm{P}_{\mathrm{i}}$ akan bernilai 1 jika $\mathrm{P} *_{i}>0$, seseorang memilih bekerja dan $P_{i}$ akan bernilai 0 jika $\mathrm{P} *_{\mathrm{i}} \leq 0$, seseorang memilih tidak bekerja. 
Tabel 1.

Definisi Operasional Variabel

\begin{tabular}{|c|c|c|}
\hline $\begin{array}{c}\text { Nama/ } \\
\text { Jenis Variabel }\end{array}$ & Notasi & Definisi Operasional \\
\hline \multicolumn{3}{|l|}{ Variabel Terikat } \\
\hline $\begin{array}{l}\text { 1. Partisipasi } \\
\text { (memiliki } \\
\text { penghasilan) }\end{array}$ & kerja & $\begin{array}{l}\text { Mereka yang statusnya bekerja (minimal } 1 \text { jam dalam } \\
\text { seminggu terakhir) dan memiliki penghasilan. } \\
\text { Dummy } 1 \text { : Jika bekerja dan memilik penghasilan } \\
\text { Dummy } 0 \text { : Jika tidak bekerja atau bekerja tetapi tidak } \\
\text { memiliki penghasilan }\end{array}$ \\
\hline 2. Penghasilan & lnhasil & $\begin{array}{l}\text { Penghasilan yang diterima seseorang selama sebulan } \\
\text { terakhir berupa upah/gaji, tunjangan, laba/keuntungan } \\
\text { usaha. } \\
\text { Dalam analisinya untuk menghindari variasi data yang } \\
\text { cukup besar digunakan fungsi logaritma natural dari } \\
\text { penghasilan tersebut. }\end{array}$ \\
\hline \multicolumn{3}{|l|}{$\underline{\text { Variabel Bebas }}$} \\
\hline 1. Umur & umur & Umur seseorang berdasarkan ulang tahun terakhir. \\
\hline 2. Jenis Kelamin & perempuan & $\begin{array}{l}\text { Jenis kelamin secara biologis. } \\
\text { Dummy } 1: \text { Jika perempuan } \\
\text { Dummy } 0: \text { Jika laki-laki }\end{array}$ \\
\hline 3. Status Kawin & kawin & $\begin{array}{l}\text { Status individu pada saat pendataan. } \\
\text { Dummy } 1: \text { Jika statusnya kawin } \\
\text { Dummy } 0: \text { Jika statusnya tidak/pernah kawin }\end{array}$ \\
\hline 4. Tempat Tinggal & kota & $\begin{array}{l}\text { Perbedaan menurut klasifikasi tempat tinggal. } \\
\text { Dummy } 1: \text { Jika tinggal di perkotaan } \\
\text { Dummy } 0: \text { Jika tinggal di perdesaan }\end{array}$ \\
\hline 5. Tingkat Pendidikan & $\begin{array}{l}\text { smp, sma, } \\
\text { smk, } \\
\text { diploma, } \\
\text { univ }\end{array}$ & $\begin{array}{l}\text { Jenjang pendidikan tinggi yang ditamatkan (ijazah } \\
\text { terakhir yang dimiliki). } \\
\text { Dummy } 1 \text { : Jika pendidikan terakhir SMP ke atas } \\
\text { Dummy } 0: \text { Jika pendidikan terakhir SD ke bawah }\end{array}$ \\
\hline 6. Jam Kerja & jam & Jumlah jam kerja selama sebulan yang lalu \\
\hline $\begin{array}{l}\text { 7. Status Dalam Rumah } \\
\text { Tangga }\end{array}$ & krt & $\begin{array}{l}\text { Status/kedudukan dalam rumah tangga. } \\
\text { Dummy } 1: \text { Jika statusnya kepala rumah tangga } \\
\text { Dummy } 0: \text { Jika statusnya bukan kepala rumah tangga }\end{array}$ \\
\hline 8. Status Pekerjaan & formal & $\begin{array}{l}\text { Status jenis pekerjaan yang dibedakan menurut } \\
\text { kategori formal/tidak. } \\
\text { Dummy } 1 \text { : Jika formal } \\
\text { Dummy } 0 \text { : Jika informal } \\
\end{array}$ \\
\hline 9. Jenis Pekerjaan & $\begin{array}{l}\text { kputih, } \\
\text { kabu2 }\end{array}$ & $\begin{array}{l}\text { Jenis pekerjaan yang dibedakan menurut jenis kerah. } \\
\text { Dummy } 1: \text { Jika termasuk pekerjaan kerah putih/abu- } \\
\text { abu } \\
\text { Dummy } 0: \text { Jika termasuk pekerjaan kerah biru }\end{array}$ \\
\hline 10. Lapangan Usaha & $\begin{array}{l}\text { manufaktur } \\
\text {, jasa }\end{array}$ & $\begin{array}{l}\text { Lapangan usaha dari pekerjaan seminggu yang lalu. } \\
\text { Dummy } 1: \text { Jika sektor manufaktur/jasa } \\
\text { Dummy } 0: \text { Jika sektor pertanian }\end{array}$ \\
\hline
\end{tabular}

Sumber: Sakernas Agustus 2019 
Model estimasi penghasilan menurut gender (Mincer, 1974) sebagai berikut:

$\ln Y_{i}=\beta_{0}+\beta_{i} X_{i}+\varepsilon_{i}$

dimana $\ln \mathrm{Y}_{\mathrm{i}}$ adalah logaritma natural dari penghasilan dan $\mathrm{X}_{\mathrm{i}}$ adalah variabel bebas yang mempengaruhi penghasilan.

Untuk mengukur adanya kesenjangan gender dalam penghasilan digunakan metode dekomposisi Blinder-Oaxaca yaitu suatu metode yang digunakan untuk mengukur perbedaan kesenjangan penghasilan yang dibedakan menurut faktor yang dapat dijelaskan (endowment) dan faktor yang tidak dapat dijelaskan (diskriminasi) (Oaxaca dan Blinder, 1973). Langkah awalnya membuat model penghasilan antar gender kemudian mendekomposisi perbedaan penghasilan tersebut menurut karakteristik faktorfaktornya. Fungsi penghasilan untuk lakilaki dan perempuan sebagai berikut:

Fungsi penghasilan laki-laki :

$\ln \mathrm{Y}_{\mathrm{im}}=\beta_{0 \mathrm{~m}}+\beta_{1 \mathrm{~m}}$ umur $_{\mathrm{m}}+\beta_{2 \mathrm{~m}}$ umur $_{\mathrm{m}}^{2}+\beta_{3 \mathrm{~m}}$ $\operatorname{kota}_{\mathrm{m}}+\beta_{4 \mathrm{~m}} \mathrm{smp}_{\mathrm{m}}+\beta_{5 \mathrm{~m}} \mathrm{sma}_{\mathrm{m}}+\beta_{6 \mathrm{~m}} \mathrm{smk}_{\mathrm{m}}+$ $\beta_{7 \mathrm{~m}}$ diploma $_{\mathrm{m}}+\beta_{8 \mathrm{~m}}$ univ $_{\mathrm{m}}+\beta_{9 \mathrm{~m}}$ jam $_{\mathrm{m}}+\beta_{10 \mathrm{~m}}$ formal $_{\mathrm{m}}+\beta_{11 \mathrm{~m}}$ kputih $_{\mathrm{m}}+\beta_{12 \mathrm{~m}}$ kabu $2_{\mathrm{m}}+$ $\beta_{13 \mathrm{~m}}$ manufaktur $_{\mathrm{m}}+\beta_{14 \mathrm{~m}}$ jasa $_{\mathrm{m}}+\beta_{15 \mathrm{~m}}$ invmills $s_{\mathrm{m}}+\varepsilon_{\mathrm{im}}$

Fungsi penghasilan perempuan :

$\ln Y_{\text {if }}=\beta_{0 f}+\beta_{1 \mathrm{f}}$ umur $_{\mathrm{f}}+\beta_{2 \mathrm{f}}$ umurf $_{\mathrm{f}}^{2}+\beta_{3 \mathrm{f}}$ kotaf $_{\mathrm{f}}$ $+\beta_{4 \mathrm{f}} \mathrm{smp}_{\mathrm{f}}+\beta_{5 \mathrm{f}} \mathrm{sma}_{\mathrm{f}}+\beta_{6 \mathrm{f}} \mathrm{smk}_{\mathrm{f}}+\beta_{7 \mathrm{f}}$ $\operatorname{diploma}_{\mathrm{f}}+\beta_{8 \mathrm{f}}$ univ $_{\mathrm{f}}+\beta_{9 \mathrm{f}} \mathrm{jam}_{\mathrm{f}}+\beta_{10 \mathrm{f}}$ formal $_{\mathrm{f}}$ $+\beta_{11 \mathrm{f}}$ kputih $_{\mathrm{f}}+\beta_{12 \mathrm{f}}$ kabu2 $\mathrm{f}+\beta_{13 \mathrm{f}}$ manufaktur $_{f}+\beta_{14 f}$ jasa $_{\mathrm{f}}+\beta_{15 \mathrm{f}}$ invmills $_{\mathrm{f}}+\varepsilon_{\text {if }}$

\section{HASIL DAN PEMBAHASAN \\ Gambaran Umum Angkatan Kerja}

Gambaran umum dari angkatan kerja hasil sampel Sakernas Agustus 2019 terangkum dalam Tabel 2. Jumlah angkatan kerja sebanyak 532.213 orang dengan 60,04 persen adalah laki-laki dan 39,96 persen perempuan. Dilihat dari karakteristik sosial demografinya terlihat bahwa angkatan kerja baik laki-laki dan perempuan mayoritas berstatus kawin, tinggal di perdesaan, tidak memiliki balita dan berpendidikan rendah. Lima puluh persen lebih angkatan kerja berpendidikan SMP ke bawah.

\section{Gambaran Umum Individu Bekerja}

Dari tabel 3 diketahui bahwa jumlah individu yang bekerja pada Agustus 2019 sebanyak 510.161 orang terdiri dari 306.335 orang laki-laki dan 203.826 orang perempuan. Secara jumlah dan persentase laki-laki lebih banyak yang bekerja dibandingkan dengan perempuan.

Persentase laki-laki sekitar 60 persen sementara perempuan sekitar 40 persen. Rata-rata umur orang yang bekerja baik laki-laki dan perempuan sekitar 41 tahun dengan rata-rata jumlah jam kerja pada lakilaki lebih banyak dibandingkan pada perempuan. Jika laki-laki dalam satu bulan rata-rata bekerja selama 168,84 jam, maka perempuan jauh lebih sedikit yaitu dengan rata-rata jam kerja 148,04 jam per bulan. Hal ini tidak mengherankan karena pada perempuan alokasi waktu yang digunakan yaitu untuk bekerja, leissure dan mengurus rumah tangga sementara laki-laki aloksi waktunya hanya untuk bekerja dan leissure. Dari segi sosial demografi terlihat bahwa orang yang bekerja mayoritas berstatus kawin, tinggal di perdesaan, tidak memiliki balita dan berpendidikan rendah. Sementara dari segi pekerjaan mayoritas laki-laki dan perempuan bekerja pada sektor formal, dengan jenis pekerjaan kerah biru dan pada lapangan usaha di sektor jasa. 


\section{Model Partisipasi Kerja}

Model probit yang terbentuk memiliki nilai -2 log likelihood uji $G$ sebesar 55.364,04 dan probability $\mathrm{Chi}^{2}$ nilainya 0,0000 sehingga dapat diartikan bahwa dengan taraf kepercayaan 95 persen (alfa 5 persen) bahwa model yang terbentuk adalah signifikan secara statistik. Jika dilihat dari tingkat signifikansi setiap variabel bebas yang digunakan maka hasil menunjukkan bahwa nilai $p$-value semua variabel bebas adalah 0,0000 yang berati bahwa secara statistik dengan tingkat kepercayaan 95 persen secara parsial masing-masing variabel bebas yang digunakan berpengaruh signifikan terhadap probabilitas seseorang untuk memilih bekerja atau tidak. Model probit yang terbentuk sebagai berikut:

$$
\mathrm{P}^{*} \mathrm{i}=-0,0800+0,0406 \text { umur-0,0006 }
$$
umur $^{2}-0,0333$ perempuan - 0,1212 kawin $+0,4125$ kota $+0,0840 \mathrm{smp}+0,1722 \mathrm{sma}$ $+0,2803 \mathrm{smk}+0,6630$ diploma $+0,8075$ univ $+0,2522 \mathrm{krt}+0,1291$ balita $-0,1404$ jkbal - 0,1552 jkkwn

Untuk melihat pengaruh dari perubahan pada variabel bebas terhadap variabel terikat maka digunakan marginal effect. Besaran dari nilai marginal effect model probit partisipasi bekerja disajikan pada Tabel 4.

Marginal effect dari umur terhadap probabilitas seseorang bekerja dengan penghasilan adalah sebesar 1,74 persen dan memiliki bentuk kuadratik dimana pada umur puncak tertentu penembahan umur justru akan membuat probabilitas seseorang untuk bekerja dengan penghasilan semakin menurun yang ditandai dengan efek pada umur $^{2}$ bernilai negatif. Probabilitas seseorang bekerja dengan penghasilan juga berbeda antar gender. Probabilitas perempuan untuk bekerja dengan penghasilan 1,26 persen lebih rendah dibandingkan dengan laki-laki. Bahkan probabilitas ini semakin menurun jika perempuan berstatus kawin dan memiliki balita. Hal ini menunjukkan bahwa hipotesis yang diajukan di awal terbukti. Hasil penelitian ini juga sejalan dengan Kusharyono, 2006 dan Berliana \& Purbasari, 2018.

Sedangkan dari segi pendidikan ternyata bahwa semakin tinggi pendidikan maka semakin besar pula probabilitas seseorang untuk bekerja dengan penghasilan. Probabilitas bekerja dengan penghasilan terbesar ada pada tingkat pendidikan universitas dimana orang-orang yang berpendidikan sampai lulus universitas 25,63 persen lebih tinggi probabilitasnya untuk bekerja dengan penghasilan dibandingkan dengan mereka yang hanya berpendidikan kurang atau sama dengan SD. (Lisa, et.al, 2019) Pendidikan tinggi dikaitkan dengan peningkatan TPAK perempuan pada usia muda, sementara tanggung jawab rumah tangga adalah penghalang utama untuk partisipasi perempuan. Sebagian besar perempuan lajang dan berpendidikan tinggi di Indonesia memasuki angkatan kerja pada usia 25 dan berpartisipasi hampir sampai pensiun. Sebaliknya, perempuan yang menikah, berpendidikan rendah, dan memiliki anak meningkatkan partisipasi angkatan kerja mereka hanya setelah usia 40 tahun. Probabilitas bekerja dengan penghasilan juga akan lebih tinggi pada mereka yang tinggal di daerah perkotaan serta statusnya sebagai kepala rumah tangga dalam keluarga.

\section{Model Penghasilan Berdasarkan Gender}

Secara keseluruhan model penghasilan baik laki-laki maupun perempuan menunjukkan bahwa modelnya fit dengan 
nilai statistik F untuk laki-laki 5.014,89 dan untuk perempuan 3.561,76 yang keduanya signifikan pada tingkat kepercayaan 95 persen. Nilai koefisien determinasi untuk model penghasilan laki-laki 26,3 persen sedangkan untuk model penghasilan perempuan 31,24 persen.

Jika dilihat secara parsial, semua variabel bebas yang digunakan dalam model berpengaruh secara signifikan pada taraf kenyakinan 95 persen (tingkat kesalahan alfa 5 persen) untuk model pada laki-laki dan perempuan, kecuali pada variabel manufaktur di model penghasilan perempuan dimana tingkat signifikansinya berada pada tingkat kesalahan alfa 10 persen. Model penghasilan menurut gender dijabarkan lebih lanjut pada Tabel 5.

Model penghasilan laki-laki:

Ln $\quad\left(\right.$ hasil $\left.l_{m}\right)=12,7154+0,0457$ umur0,0005 umur $^{2}+0,0264$ kota $+0,0979 \mathrm{smp}$ $+0,2587 \mathrm{sma}+0,2539 \mathrm{smk}+0,3748$ diploma $+0,5002$ univ $+0,0032$

jam + 0,2093 formal $+0,1491$ kputih + 0,0779 kabu $2+0,1720$ manufaktur + 0,0345 jasa - 0,4416 invmills

Model penghasilan perempuan:

Ln $\left(\right.$ hasil $\left._{\mathrm{f}}\right)=11,2669+0,0581$ umur0,0006 umur $^{2}+0,2602$ kota $+0,2127 \mathrm{smp}$ $+0,4150 \mathrm{sma}+0,5137 \mathrm{smk}+0,7630$ diploma $+0,8844$ univ $+0,0045$ jam + 0,1950 formal $+0,1562$ kputih $+0,0557$ kabu $2+0,0157$ manufaktur $-0,0351$ jasa + 0,1234 invmills

Dari hasil model penghasilan menurut jenis kelamin, umur berpengaruh secara kuadratik terhadap penghasilan. Hal ini menunjukkan bahwa penghasilan seseorang akan semakin meningkat dengan bertambahnya usia, akan tetapi sampai pada puncak usia tertentu kemudian penghasilan akan mulai menunjukkan penurunan, asumsi ceteris paribus. Pada laki-laki umur puncak penghasilan yaitu di usia 45,7 tahun sementara untuk perempuan di usia 48,4 tahun. Dari segi pendidikan, baik laki-laki dan perempuan menunjukkan nilai yang positif yang berati bahwa semakin tinggi pendidikan maka semakin besar pula penghasilan yang akan diperoleh. Hal ini tentunya sejalan dengan teori human capital bahwasanya pendidikan adalah proxy dari produktiftas pekerja, dimana semakin tinggi pendidikan maka diasumsikan produktifitasnya semakin besar pula bagi perusahaan. Besaran pengaruh dari setiap jenjang pendidikan bagi laki-laki dan perempuan terhadap penghasilan lebih detal seperti pada Tabel 5.

Penghasilan laki-laki yang tinggal di perkotaan lebih tinggi 2,6 persen dibandingkan mereka yang tinggal di perdesaan, sedangkan untuk penghasilan perempuan di perkotaan lebih tinggi 26 persen dibandingkan mereka yang tinggal di perdesaan, asumsi ceteris paribus. Jumlah jam kerja memiliki pengaruh yang signifikan terhadap penghasilan yang diterima laki-laki dan perempuan. Setiap kenaikan jam kerja selama 1 jam akan meningkatkan penghasilan laki-laki sebesar 0,32 persen dan untuk perempuan 0,45 persen, asumsi ceteris paribus. Dari status pekerjaan, penghasilan yang diterima oleh mereka yang bekerja di sektor formal lebih tinggi dibandingkan dengan mereka yang bekerja di sektor informal. Laki-laki memperoleh penghasilan 20,9 persen dan perempuan 19,5 persen lebih tinggi jika mereka bekerja pada jenis pekerjaan formal, asumsi ceteris paribus. Jenis pekerjaan kerah putih memiliki pengaruh yang paling tinggi pada penghasilan jika dibandingkan dengan jenis pekerjaan kerah biru ataupun 
abu-abu. Laki-laki yang bekerja pada jenis pekerjaan kerah putih memperoleh penghasilan 14,91 persen lebih tinggi dan perempuan 15,62 persen lebih tinggi, asumsi ceteris paribus. Dilihat dari sektor lapangan usaha dari bidang pekerjaan yang dimiliki, ternyata penghasilan laki-laki yang bekerja pada sektor manufaktur 7,2 persen lebih tinggi dibandingkan mereka yang bekerja pada sektor pertanian, asumsi ceteris paribus. Sedangkan penghasilan perempuan yang bekerja pada sektor manufaktur 1,57 persen lebih tinggi dibandingkan mereka yang bekerja pada sektor pertanian, asumsi ceteris paribus. Sementara itu efek yang berbeda ada pada pekerjaan di sektor jasa. Jika penghasilan laki-laki yang bekerja di sektor jasa lebih tinggi dibandingkan dengan mereka yang bekerja pada sektor pertanian, hal sebaliknya justru terjadi pada penghasilan perempuan. Penghasilan perempuan yang bekerja pada sektor jasa 3,5 persen lebih rendah dibandingkan mereka yang bekerja pada sektor pertanian, asumsi ceteris paribus.

\section{Kesenjangan Penghasilan Antar Gender}

Untuk mengukur kesenjangan antar gender digunakan metode dekomposisi Blinder-Oaxaca. Selain dapat menunjukkan seberapa besar nilai kesenjangan penghasilan yang terjadi, metode ini juga dapat menunjukkan seberapa besar perbedaan yang terjadi akibat faktor endowment (yang dapat dijelaskan melalui karakteristik observasi) dan juga faktor diskriminasi (yang tidak diobservasi). Hasil dekomposisi Blinder-Oaxaca disajikan pada Tabel 6.

Kesenjangan penghasilan antar gender berdasarkan hasil dekomposisi BlinderOaxaca di Indonesia tahun 2019 sebesar 0,4282. Artinya secara rata-rata laki-laki memperoleh penghasilan 42,82 persen lebih tinggi jika dibandingkan dengan perempuan. Besaran kesenjangan ini hanya 3,5 persen yang dapat dijelaskan oleh perbedaan karakteristik pada laki-laki dan perempuan atau yang disebut dengan perbedaan karena faktor endowment. Sementara itu 96,45 persen perbedaan penghasilan justru disebabkan oleh faktor yang tidak dapat dijelaskan. Hal ini menunjukkan bahwasanya terjadi diskriminasi penghasilan di pasar kerja Indonesia.

Diskriminasi dalam pasar kerja dapat terjadi karena setidaknya ada 2 hal, yaitu budaya patriarki (orang tua lebih mementingkan pendidikan anak laki-laki, anggapan bahwa perempuan bertanggungjawab terhadap urusan rumah tangga, laki-laki yang bekerja) dan juga adanya anggapan negatif pada rendahnya produktifitas perempuan akibat absensinya ketika harus melahirkan dan lain sebagainya (Ozcan dkk, 2003). Oleh karena diskriminasi tersebutlah rata-rata penghasilan perempuan jauh lebih rendah dibandingkan dengan laki-laki.

Dari variabel endowment yang terdapat pada Tabel 4.5, tanda positif menunjukkan bahwa variabel tersebut memiliki pengaruh yang akan meningkatkan kesenjangan penghasilan antar gender. Variabel yang bertanda positif yaitu umur, jam kerja dan lapangan usaha, dimana jam kerja adalah variabel yang menyebabkan tingkat kesenjangan penghasilan terbesar yaitu 7,44 persen. Sedangkan variabel yang bertanda negatif artinya variabel tersebut justru akan memperkecil kesenjangan penghasilan antar gender. Variabel yang bertanda negatif dari hasil penelitian adalah tempat tinggal, pendidikan, status pekerjaan, dan jenis pekerjaan. 
Tabel 2.

Deskripsi Angkatan Kerja Menurut Jenis Kelamin dan Karakteristik Sosial dan Demografi, Agustus 2019

\begin{tabular}{|c|c|c|c|c|}
\hline \multicolumn{2}{|c|}{ Karakteristik } & Laki-laki & Perempuan & Total \\
\hline \multicolumn{2}{|l|}{ Umur (Tahun) } & 41,31 & 41,29 & 41,30 \\
\hline \multirow[t]{4}{*}{ Status Kawin (\%) } & Kawin & 75,09 & 70,68 & 73,33 \\
\hline & Tidak/Pernah & 24,91 & 29,32 & 26,67 \\
\hline & Kawin & & & \\
\hline & Total & 100,00 & 100,00 & 100,00 \\
\hline \multirow{3}{*}{$\begin{array}{l}\text { Tempat } \\
(\%)\end{array}$} & Perkotaan & 42,09 & 42,49 & 42,25 \\
\hline & Perdesaan & 57,91 & 57,51 & 57,75 \\
\hline & Total & 100,00 & 100,00 & 100,00 \\
\hline \multirow{7}{*}{$\begin{array}{l}\text { Pendidikan yang } \\
\text { ditamatkan }(\%)\end{array}$} & $\leq \mathrm{SD}$ & 40,56 & 44,15 & 41,99 \\
\hline & SMP & 18,05 & 15,72 & 17,12 \\
\hline & SMA & 20,58 & 16,64 & 19,01 \\
\hline & SMK & 10,78 & 7,77 & 9,58 \\
\hline & Diploma & 1,91 & 3,73 & 2,64 \\
\hline & Universitas & 8,12 & 11,99 & 9,67 \\
\hline & Total & 100,00 & 100,00 & 100,00 \\
\hline \multirow[t]{3}{*}{ Balita (\%) } & Ada & 27,66 & 23,86 & 25,95 \\
\hline & Tidak Ada & 72,66 & 76,14 & 74,05 \\
\hline & Total & 100,00 & 100,00 & 100,00 \\
\hline \multicolumn{2}{|l|}{ Observasi } & 319.534 & 212.679 & 532.213 \\
\hline \multicolumn{2}{|l|}{ Observasi (\%) } & 60,04 & 39,96 & 100,00 \\
\hline
\end{tabular}

Sumber : Sakernas Agustus 2019, diolah

Tabel 3.

Deskripsi Individu Bekerja Menurut Jenis Kelamin dan Karakteristik Sosial dan Demografi, Agustus 2019

\begin{tabular}{|c|c|c|c|c|}
\hline \multicolumn{2}{|c|}{ Karakteristik } & \multirow{2}{*}{$\begin{array}{c}\begin{array}{c}\text { Laki- } \\
\text { laki }\end{array} \\
41,87\end{array}$} & \multirow{2}{*}{$\begin{array}{c}\text { Perempuan } \\
41,90\end{array}$} & \multirow{2}{*}{\begin{tabular}{|l|} 
Total \\
41,88 \\
\end{tabular}} \\
\hline Umur (Tahun) & & & & \\
\hline \multirow[t]{4}{*}{ Status Kawin $(\%)$} & Kawin & 77,24 & 72,39 & 75,30 \\
\hline & Tidak/Pernah & 22,76 & 27,61 & 24,70 \\
\hline & Kawin & & & \\
\hline & Total & 100,00 & 100,00 & 100,00 \\
\hline \multirow[t]{3}{*}{ Tempat Tinggal (\%) } & Perkotaan & 41,36 & 41,97 & 41,60 \\
\hline & Perdesaan & 58,64 & 58,03 & 58,40 \\
\hline & Total & 100,00 & 100,00 & 100,00 \\
\hline \multirow{2}{*}{$\begin{array}{l}\text { Pendidikan yang } \\
\text { ditamatkan }(\%)\end{array}$} & $\leq \mathrm{SD}$ & 41,46 & 45,36 & 43,02 \\
\hline & SMP & 18,13 & 15,83 & 17,21 \\
\hline
\end{tabular}




\begin{tabular}{|c|c|c|c|c|}
\hline \multicolumn{2}{|c|}{ Karakteristik } & \multirow{2}{*}{$\begin{array}{c}\text { Laki- } \\
\text { laki }\end{array}$} & \multirow{2}{*}{$\begin{array}{c}\text { Perempuan } \\
15,97\end{array}$} & \multirow{2}{*}{$\begin{array}{c}\text { Total } \\
18,47\end{array}$} \\
\hline & SMA & & & \\
\hline & SMK & 10,28 & 7,28 & 9,08 \\
\hline & Diploma & 1,90 & 3,68 & 2,61 \\
\hline & Universitas & 8,09 & 11,89 & 9,61 \\
\hline & Total & 100,00 & 100,00 & 100,00 \\
\hline \multirow[t]{3}{*}{ Balita $(\%)$} & Ada & 27,72 & 23,90 & 26,19 \\
\hline & Tidak Ada & 72,28 & 76,10 & 73,81 \\
\hline & Total & 100,00 & 100,00 & 100,00 \\
\hline \multicolumn{2}{|c|}{ Jam Kerja (Rata-rata per bulan) (Jam) } & 168,84 & 148,04 & 160,53 \\
\hline \multirow[t]{3}{*}{ Status Pekerjaan } & Formal & 42,12 & 33,78 & 38,79 \\
\hline & Informal & 57,88 & 66,22 & 61,21 \\
\hline & Total & 100,00 & 100,00 & 100,00 \\
\hline \multirow[t]{4}{*}{ Jenis Pekerjaan } & Kerah Putih & 12,56 & 18,19 & 14,81 \\
\hline & Kerah Abu-abu & 15,72 & 31,76 & 22,13 \\
\hline & Kerah Biru & 71,72 & 50,05 & 63,06 \\
\hline & Total & 100,00 & 100,00 & 100,00 \\
\hline \multirow[t]{4}{*}{ Lapangan Usaha } & Pertanian & 38,76 & 33,11 & 36,36 \\
\hline & Manufaktur & 22,72 & 13,79 & 19,15 \\
\hline & Jasa & 38,76 & 53,09 & 44,49 \\
\hline & Total & 100,00 & 100,00 & 100,00 \\
\hline \multicolumn{2}{|l|}{ Observasi } & 306.335 & 203.826 & 510.161 \\
\hline \multicolumn{2}{|l|}{ Observasi (\%) } & 60,05 & 39,95 & 100,00 \\
\hline
\end{tabular}

Sumber : Sakernas Agustus 2019, diolah

Tabel 4.

Marginal Effect Variabel Bebas Pada Fungsi Probabilitas Bekerja Dengan Penghasilan, Agustus 2019

\begin{tabular}{lcc}
\hline \multicolumn{1}{c}{ Variabel } & dy/dx & $\boldsymbol{P}>|\boldsymbol{z}|$ \\
\hline Umur & 0,0174 & 0,000 \\
Umur $^{2}$ & $-0,0002$ & 0,000 \\
Jenis Kelamin & & \\
Laki-laki (acuan) & & \\
Perempuan & $-0,0126$ & 0,000 \\
Status Kawin & & \\
Kawin & $-0,0454$ & 0,000 \\
Tidak/Pernah Kawin (acuan) & & \\
Wilayah Tempat Tinggal & & \\
Perkotaan & 0,1533 & 0,000 \\
\hline
\end{tabular}




\begin{tabular}{lcc}
\hline \multicolumn{1}{c}{ Variabel } & dy/dx & $\boldsymbol{P}>|\mathbf{z}|$ \\
\hline Perdesaan (acuan) & & \\
Tingkat Pendidikan & & \\
$\leq$ SD (acuan) & & \\
SMP & 0,3147 & 0,000 \\
SMA & 0,0638 & 0,000 \\
SMK & 0,1012 & 0,000 \\
Diploma & 0,2130 & 0,000 \\
Universitas & 0,2563 & 0,000 \\
Status di Rumah Tangga & & \\
KRT & 0,0951 & 0,000 \\
Bukan KRT (acuan) & & \\
Balita & & \\
Ada Balita & 0,0483 & 0,000 \\
Tidak Ada Balita (acuan) & & \\
Perempuan*Balita & $-0,0539$ & 0,000 \\
Perempuan*Kawin & $-0,0592$ & 0,000 \\
\hline
\end{tabular}

Sumber : Sakernas Agustus 2019, diolah

Tabel 5.

Model Penghasilan Berdasarkan Gender, Agustus 2019

\begin{tabular}{lcccc}
\hline \multirow{2}{*}{ Variabel } & \multicolumn{2}{c}{ Laki-laki } & \multicolumn{2}{c}{ Perempuan } \\
\cline { 2 - 5 } & Koefisien & $\boldsymbol{P}>|\boldsymbol{z}|$ & Koefisien & $\boldsymbol{P}>|\boldsymbol{z}|$ \\
\hline Umur & 0,0457 & 0,000 & 0,0581 & 0,000 \\
Umur $^{2}$ & $-0,0005$ & 0,000 & $-0,0006$ & 0,000 \\
Wil Tempat Tinggal & & & & \\
Perkotaan & 0,0264 & 0,000 & 0,2602 & 0,000 \\
Perdesaan (acuan) & & & & \\
Tingkat Pendidikan & & & & \\
$\leq$ SD (acuan) & & & & \\
SMP & 0,0979 & 0,000 & 0,2127 & 0,000 \\
SMA & 0,2587 & 0,000 & 0,4150 & 0,000 \\
SMK & 0,2539 & 0,000 & 0,5137 & 0,000 \\
Diploma & 0,3748 & 0,000 & 0,7630 & 0,000 \\
Universitas & 0,5002 & 0,000 & 0,8844 & 0,000 \\
\hline
\end{tabular}




\begin{tabular}{lcccc}
\hline \multirow{2}{*}{ Variabel } & \multicolumn{2}{c}{ Laki-laki } & \multicolumn{2}{c}{ Perempuan } \\
\cline { 2 - 5 } & Koefisien & $\boldsymbol{P}>|\mathbf{z}|$ & Koefisien & $\boldsymbol{P}>|\mathbf{z}|$ \\
\hline Jam Kerja & 0,0032 & 0,000 & 0,0045 & 0,000 \\
Status Pekerjaan & & & & \\
Formal & 0,2093 & 0,000 & 0,1950 & 0,000 \\
Informal (acuan) & & & & \\
Jenis Pekerjaan & & & & \\
Kerah Putih & 0,1491 & 0,000 & 0,1562 & 0,000 \\
Kerah Abu-abu & 0,0779 & 0,000 & 0,0557 & 0,000 \\
Kerah Biru (acuan) & & & & \\
Lapangan Usaha & & & & \\
Pertanian (acuan) & & & & \\
Manufaktur & 0,1720 & 0,000 & 0,0157 & 0,078 \\
Jasa & 0,0345 & 0,000 & $-0,0351$ & 0,001 \\
Invmills & $-0,4416$ & 0,000 & 0,1234 & 0,000 \\
Const & 12,7154 & 0,000 & 11,2669 & 0,000 \\
\hline & & & & \\
\hline
\end{tabular}

Sumber : Sakernas Agustus 2019, diolah

Tabel 6.

Dekomposisi Kesenjangan Antar Gender di Indonesia, 2019

\begin{tabular}{|c|c|c|c|}
\hline Variabel & $\begin{array}{c}\text { Total } \\
\text { Kesenjangan }\end{array}$ & $\begin{array}{c}\text { Faktor } \\
\text { Endowment }\end{array}$ & $\begin{array}{c}\text { Faktor } \\
\text { Diskriminasi }\end{array}$ \\
\hline Umur & & 0,0035 & \\
\hline Tempat Tinggal & & $-0,0057$ & \\
\hline Pendidikan & & $-0,0478$ & \\
\hline Jam Kerja & & 0,0744 & \\
\hline Status Pekerjaan & & $-0,0019$ & \\
\hline Jenis Pekerjaan & & $-0,0379$ & \\
\hline Lapangan Usaha & & 0,0121 & \\
\hline Invmills & & 0,0185 & \\
\hline Total & 0,4282 & 0,0152 & $\mathbf{0 , 4 1 3 0}$ \\
\hline Total $(\%)$ & 100,00 & 3,55 & 96,45 \\
\hline
\end{tabular}

Sumber : Sakernas Agustus 2019, diolah 


\section{SIMPULAN}

Berdasarkan analisis yang telah dilakukan dalam penelitian ini dapat disimpulkan beberapa hal antara lain : tingkat partisipasi angkatan kerja perempuan di Indonesia cenderung stagnan. Model partisipasi kerja perempuan memberikan informasi bahwa probabilitas seorang untuk berpartisipasi dalam angkatan kerja semakin kecil jika berstatus kawin dan memiliki balita. Dari model penghasilan menurut gender, laki-laki dan perempuan akan cenderung memiliki penghasilan yang lebih tinggi jika semakin tinggi pendidikan, tinggal di perkotaan, jam kerja semakin banyak, bekerja pada pekerjaan formal, jenis pekerjaan kerah putih dan lapangan usaha di sektor manufaktur. Kesenjangan penghasilan antar gender berdasarkan hasil dekomposisi Blinder-Oaxaca di Indonesia tahun 2019 sebesar 0,4282.

Besaran kesenjangan ini hanya 3,5 persen yang disebabkan karena faktor endowment, sementara itu 96,45 persen disebabkan oleh faktor diskriminasi. Terlihat bahwa faktor endowment memiliki kontribusi yang lebih rendah jika dibandingkan dengan faktor diskriminasi. Melihat besarnya faktor diskriminasi pada kesenjangan penghasilan antar gender di Indonesia, perlu kiranya peran pemerintah dalam mensosialisasikan kebijakankebijakan yang terkait dengan persamaan gender khususnya dalam dunia kerja. Misalnya saja dengan memaksimalkan para pelaku usaha agar dapat melaksanakan amanat UU no 13 tahun 2003 tentang ketenagakerjaan dimana salah satunya tentang diskriminasi gender yang seharusnya tidak terjadi di lingkungan pasar kerja. Selain itu untuk meningkatkan kontribusi perempuan di pasar kerja perlu juga untuk meningkatkan pendidikan dasar khususnya bagi para perempuan sehingga dengan pendidikan yang semakin tinggi akan membuat mereka memiliki kesempatan daya saing yang lebih besar di pasar kerja.

Penelitian ini masih belum memasukkan variabel-variabel lain yang mungkin dapat menjelaskan lebih detail mengenai kesenjangan gender yang terjadi di Indonesia. Misalnya saja skala perusahaan/tempat bekerja, lama kerja/lama berusaha, dan lain sebagainya. Akan lebih baik lagi jika dapat memasukkan variabel penjelas yang lain dengan melihat juga tren untuk beberapa series tahun/waktu.

\section{DAFTAR PUSTAKA}

Anker, Richard. (1998). Gender and Jobs : Sex Segregation of Occupations in The World. United Kingdom : International Labour Office Genewa

Agustini, Ratna. (2016). Analisis Partisipasi Angkatan Kerja Wanita Kota Metropolitan Di Indonesia. Skripsi. Universitas Airlangga.

Berliana, S.M., dan Purbasari, L.A., (2018). Faktor-faktor yang Memengaruhi Jam kerja Wanita Berstatus Kawin Dalam Seminggu di Indonesia. Jurnal Ilmiah Widya. Vol 4 no 3.

Blinder, A. S. (1973). Wage discrimination: Reduced form and structural estimates. The Journal of Human Resources, 8(4), 436-455. doi:10.2307/144855 
Borjas, G.J., (2016). Labor Economics Seventh Edition. United States: Mc Graw Hill Education

BPS. (2019). Keadaan Angkatan Kerja di Indonesia Agustus 2019. Jakarta: BPS. (2019). Keadaan Pekerja di Indonesia Agustus 2019. Jakarta: BPS.

Cameron, L., Suarez, D.C., \& Rowell, W. (2019). Female Labour Force Participation in Indonesia: Why Has it Stalled?, Bulletin of Indonesian Economic Studies, 55:2, 157-192, DOI: 10.1080/00074918.2018.1530727

Caroline Rubin, B. . (2020). The Gender Wage Gap in Indonesia. In Georgetown University (Vol. 21, Issue 1). https://doi.org/10.1016/j.solener.2019.02.027

Heckman, J. J. (1979). Sample selection bias as a specification error. Econometrica, 47(1), 153-161. doi:10.2307/1912352

Jacobson, J.P., (1994). Sex Segregation at Work: Trends and Predictions. Social Science Journal, 31:2, 153-169

Kusharyono, -. (2009). Pengaruh Keberadaan Anak 0-6 Tahun dan ART Lain Terhadap Penawaran Tenaga Kerja Perempuan Kawin di Jawa Tengah (Susenas 2006).

Lidya, S. W., \& Kadir, K. (2019). Decomposition of the Gender Wage Gap in Indonesia: Analysis from Sakernas Data. Economic Policy, 2116, 0-33.

Mardiana, M. (2014). Kesenjangan Penghasilan antar Gender Para Wirausaha dan Pekerja Tahun 2013. Thesis. Depok : Universitas Indonesia.

Mardiana, M. (2015). Kesenjangan Penghasilan antar Gender di Indonesia Tahun 2013 dengan Metode Dekomposisi Blinder-Oaxaca. Jurnal Aplikasi Statistika \& Komputasi Statistik, 7(1), 20. doi:10.34123/jurnalasks.v7i1.116

Oaxaca, R. (1973). Male-female wage differentials in urban labor markets. International Economic Review, 14(3), 693-709. doi:10.2307/2525981

Ozcan, Yusuf Ziya., Senay Ucdogruk, dan Kivilcim Metin Ozcan. (2003). Wage Differences by Gender, Wage and Self Employment in Urban Turkey. Journal of Economic Cooperation 24, pp.1-24.

Pratomo, D.S, (2017). Pendidikan dan Partisipasi Angkatan Kerja Wanita di Indonesia: Analisis Terhadap Hipotesis Kurva -U. Jurnal Ekonomi Kuantitatif Terapan. 10:(2).

Rahman, M., \& Al-Hasan, M. (2019). Male-Female Wage Gap and Informal Employment in Bangladesh: A Quantile Regression Approach. South Asia Economic Journal, 20(1), 106123. https://doi.org/10.1177/1391561418824477

Sohn, K., (2015). Gender Discrimination in Earnings in Indonesia: A Fuller Picture. Bulletin of Indonesian Economic Studies, 51:1, 95-121, DOI:10.1080/00074918.2015.1016569.

World Economic Forum. (2019). Global Gender Gap Report 2020: Insight Report. Switzerland. http://www3.weforum.org/docs/WEF_GGGR_2020.pdf 